\title{
Who's in CHARGE? Multidisciplinary management of patients with CHARGE association
}

\author{
K D Blake, I M Russell-Eggitt, D W Morgan, J M Ratcliffe, R K H Wyse
}

\begin{abstract}
Clinical experience of 50 patients with the CHARGE association is reviewed and problems with management of children born with multiple system involvement is highlighted. It was found that the outlook for survival was poor if more than one of the following three features was present: cyanotic cardiac lesions, bilateral posterior choanal atresia, or tracheo-oesophageal fistula. Mortality was largely due not to the structural heart defects or choanal abnormalities, but reflected underlying pharyngeal and laryngeal incoordination, which resulted in aspiration of secretions. Outcome is likely to be improved if collaboration between specialist surgical teams allows necessary procedures to be performed using the minimum number of anaesthetics. Examination of both the short and long term management of these children has stressed the importance of a multidisciplinary approach to their care.
\end{abstract}

CHARGE association was first described by Hall et al in $1979,{ }^{1}$ but the acronym CHARGE (Colobomata, Heart defect, choanal Atresia, growth and/or developmental Retardation, Genital hypoplasia, Ear abnormalities) was initially coined by Pagon et al in $1981 .^{2}$ Since then it has become clear that facial palsy, renal abnormalities, orofacial clefts, and oesophageal atresia frequently accompany the main features. ${ }^{34}$ Despite extensive description of the features that comprise the CHARGE acronym, there have been virtually no reports of the management, outcome, and survival of these patients. As the number of patients with CHARGE association who have attended this hospital far exceeds any published series, we felt it appropriate to describe our multidisciplinary experience in the clinical management of these patients. We also felt it important to consider, from all the clinical specialities that inevitably become involved in the management of these patients, which team should be in charge of organising long term care?

\section{Patients and methods}

The study comprised 50 patients with CHARGE association; 29 were boys and 21 were girls. All patients were referred from district general hospitals to one of the following departments within this institution: cardiology, respiratory medicine, gastroenterology, ear, nose, and throat, ophthalmology, and genetics. The criteria for inclusion in this study required that patients should exhibit at least four of the major abnormalities listed by Pagon et al. ${ }^{2}$

Detailed information on the precise range of abnormalities presented by each patient as well as their medical and surgical management was stored on an Amdahl mainframe computer. Data was analysed using an SAS statistical package and employing $\chi^{2}$ and Kaplan-Meier actuarial survival analysis as appropriate.

\section{Results}

ACTUARIAL SURVIVAL ANALYSIS

Of the 50 patients with CHARGE association, 13 have died (nine boys and four girls). Actuarial survival analysis (fig 1) was $70 \%$ at five years and showed that, of those who died, most succumbed in the first year of life. Three patients died as neonates, seven died between 1 month and 1 year of age, and three died between 1 and 5 years of age. Seven of these 13 patients (54\%) died of aspiration. Considering that a further five patients had either withdrawal of support or sudden death (cause unknown), aspiration of secretions may clearly represent the major incremental risk factor (table 1).

\section{SURGICAL MANAGEMENT}

Thirty two patients presented with cyanosis, which was due to congenital heart disease in 12 , choanal atresia in 12, and to a combination of heart disease and choanal atresia in eight.

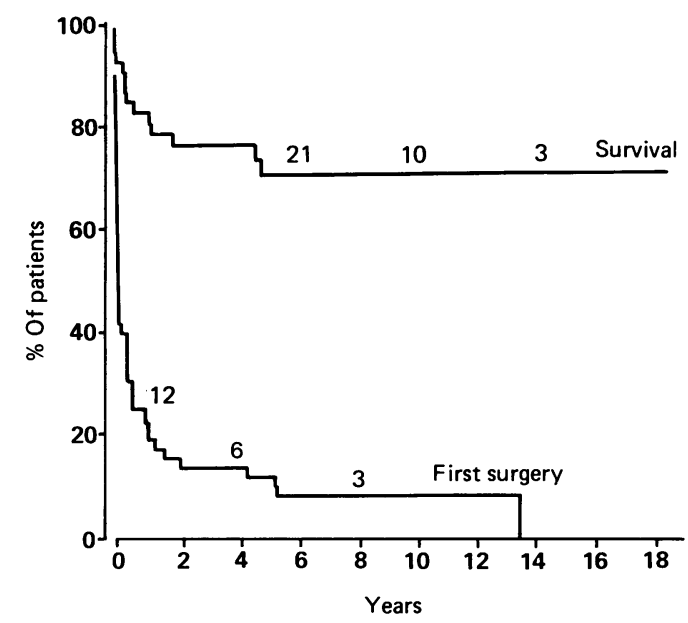

Figure 1 Upper curve: Kaplan-Meier actuarial survival of 50 patients with CHARGE association. Numbers along the curve portray how many patients were still being followed up. Lower curve: actuarial analysis of the time elapsed before each patient with CHARGE association required their first surgical procedure. 
Table 1 Details of children who died $(n=13)$

\begin{tabular}{l}
\hline $\begin{array}{c}\text { No of } \\
\text { patients }\end{array}$ \\
$\begin{array}{l}\text { Died<1 month } \\
\text { postoperatively }\end{array}$ \\
$\begin{array}{l}\text { Died of aspiration } \\
\text { pneumonia }\end{array}$ \\
$\begin{array}{l}\text { Decision to adopt no } \\
\text { active treatment }\end{array}$ \\
$\begin{array}{l}\text { Sudden death: cause } \\
\text { unknown }\end{array}$ \\
*These seven children died \\
from aspiration ( $\mathrm{n}=5)$, dis- \\
seminated intravascular coa- \\
gulation from sepsis ( $\mathrm{n}=1$ ), \\
and withdrawal of treatment \\
$(\mathrm{n}=1)$.
\end{tabular}

and withdrawal of treatment

$(\mathbf{n}=1)$
The actuarial probability of patients with CHARGE association requiring at least one major surgical intervention is shown in fig 1 . Twenty six patients (52\%) required surgery as neonates (table 2). By 1 year of age nearly three quarters of the patients had undergone some form of major surgery and a further five have needed a general anaesthetic for 'minor' procedures.

The 50 patients in the study have so far required 114 major surgical procedures (average: $2 \cdot 3 /$ patient). Patients with bilateral posterior choanal atresia received proportionally more surgical procedures (2.8/patient) and investigations under general anaesthetic $(4 \cdot 7 /$ patient) than the remainder who required only 1.6 surgical procedures/patient and $3 \cdot 3$ investigations/patient.

Only two patients have not required any surgery; in contrast, two patients have needed eight major operations. Although reoperations were predominantly for choanal dilatation, cardiac repair, or insertion of grommets, a number of patients required genitourinary, ophthalmic, or plastic surgery. Six patients underwent repair of cleft palate, three patients had operations for skeletal abnormalities, one needed aspiration of a cerebral abcess, and another required excision of occipital encephalocele.

Furthermore, there were 12 Nissen fundoplication operations for gastro-oesophageal reflux or formation of a feeding gastrostomy and seven patients needed a tracheostomy. Four patients required both operations and, although these four may have been expected to have the most severe defects, none of them had bilateral posterior choanal atresia.

Half of the children who survived more than one year had needed at least one operation for myringotomies, a third required microlaryngobronchoscopy (average of two repeats/ patient), a quarter needed some form of eye surgery, and nearly a quarter of the boys had orchidopexy.

We found that patients with CHARGE association had a high postoperative mortality. There was no correlation with the type of surgery, but of those who died all had at least three general anaesthetics before death, including one patient who had 12 .

It was not possible by retrospective analysis to predict with certainty those patients who represented a high operative risk (table 1) but certain combinations of features seemed to predispose to a poor outcome, particularly bilateral posterior choanal atresia combined either with cyanotic heart disease or trahceo-oesophageal fistula (table 3 ).

Table 2 Details of neonatal surgery $(n=26)$

\begin{tabular}{lc}
\hline & No of patients \\
\hline Choanal atresia repair & 10 \\
Tracheo-oesophageal fistula & 5 \\
Cardiac surgery & $7^{*}$ \\
Tracheostomy & 2 \\
Inguinal hernia & 1 \\
Cutback for imperforate anus & 1 \\
\hline
\end{tabular}

*Four were palliative.
Table 3 Outcome

\begin{tabular}{|c|c|c|c|c|}
\hline $\begin{array}{l}\text { Abnormality } \\
\text { or risk } \\
\text { factor }\end{array}$ & $\begin{array}{l}\text { Total } \\
\text { No }\end{array}$ & Alive & Dead & $\stackrel{\%}{\text { Mortality }}$ \\
\hline Bilateral choanal atresia & 16 & 9 & 7 & 44 \\
\hline $\begin{array}{l}\text { presenting in first week } \\
\text { Bilateral choanal atresia } \\
\text { and cyanotic heart }\end{array}$ & 21 & 10 & 11 & 52 \\
\hline $\begin{array}{l}\text { and cyanotic heart } \\
\text { disease } \\
\text { Tracheo-oesophageal }\end{array}$ & 7 & 1 & 6 & 86 \\
\hline $\begin{array}{l}\text { atresia and fistula } \\
\text { Tracheo-oesophageal }\end{array}$ & 5 & 2 & 3 & 60 \\
\hline $\begin{array}{l}\text { choanal atresia } \\
\text { Tracheo-oesophageal }\end{array}$ & 2 & 0 & 2 & 100 \\
\hline $\begin{array}{l}\text { fistula and cyanotic heart } \\
\text { disease }\end{array}$ & 4 & 1 & 3 & 75 \\
\hline $\begin{array}{l}\text { Given prostagladin E2 } \\
\text { Tracheostomy }\end{array}$ & $\begin{array}{l}8 \\
7\end{array}$ & $\begin{array}{l}1 \\
4\end{array}$ & $\begin{array}{l}7 \\
3\end{array}$ & $\begin{array}{l}87 \\
43\end{array}$ \\
\hline
\end{tabular}

CONGENITAL HEART DISEASE

Congenital heart disease was present in 42 (84\%) patients; the other eight had normal hearts. The range of cardiac malformations varied but there was a preponderance of right sided lesions. Thirty patients had major congenital heart disease (defined as requiring surgery) (table 4), six of whom also had aberrant subclavian arteries.

Patent ductus arteriosus was associated with severe cardiac lesions in 19 patients: 13 were large enough to require surgical closure, five closed spontaneously, and in one patient, who subsequently died, it was not treated at the request of the parents.

Twelve patients had (haemodynamically) comparatively mild heart defects: either a small atrial or ventricular septal defect, pulmonary stenosis, patent ductus arteriosus, or a combination of these.

\section{RESPIRATORY PROBLEMS}

Twenty eight (56\%) patients had choanal atresia or stenosis and $19(38 \%)$ had no defect; three were not examined.

Sixteen patients had bilateral posterior choanal atresia (BPCA), and a high proportion of these (nine of $16,56 \%$ ) also had facial palsy.

Table 4 Range of congenital heart disease in patients requiring cardiothoracic surgery $(n=30)$

\begin{tabular}{ll}
\hline Congenital heart defect & No of patients \\
\hline Tetralogy of Fallot & 4 \\
Fallot with AVSD & 4 \\
Fallot with Ebstein's anomaly & 1 \\
AVSD alone & 2 \\
AVSD with DORV & 1 \\
AVSD with TAPVC & 1 \\
Pulmonary atresia/VSD & 1 \\
DILV with SRAVV and pulmonary stenosis & 1 \\
DORV with pulmonary stenosis and VSD & 1 \\
Pulmonary stenosis with aortic stenosis & 1 \\
Pulmonary stenosis and secundum ASD & 1 \\
TGA with pulmonary stenosis & 2 \\
VSD and PDA & 2 \\
VSD and secundum ASD & 1 \\
VSD with Ebstein's anomaly & 2 \\
VSD & 2 \\
Secundum ASD and PDA & 1 \\
Coarctation of the aorta and PDA &
\end{tabular}

ASD, atrial septal defect; AVSD, atrioventricular septal defect; DILV, double inlet left ventricle; DORV, double outlet righ ventricle; PDA, patent ductus arteriosus; SRAVV, straddling right atrioventricular valve; TAPVC, total anomalous pulmonary venous connection; TGA, transposition of great arteries; and VSD, ventricular septal defect. 
Ten children with BPCA were alive at 18 months of age, all had severe feeding problems and exhibited a pronounced failure to thrive. They all required grommets, and all showed more severe developmental retardation than the children without BPCA. Of these 10 survivors, eight had inner ear problems ranging from severe sensorineural deafness to structural temporal bone defects, eight had gastrooesophageal reflux of whom two required Nissen's fundoplication, four had laryngeal problems, and three needed a tracheostomy. Children with BPCA required more operations and investigations than the other CHARGE patients and, as a consequence, they spent substantially more time in hospital. In contrast, none of the nine patients who had either unilateral choanal atresia or stenosis died and only two of them required grommets.

Polyhyramnios can be a predictor for BPCA; of the eight children born to mothers with polyhydramnios, seven had BPCA.

\section{EAR ABNORMALITIES}

All 50 patients had abnormal pinnae or deafness, or both. Most patients (94\%) had the typical external features of lop or cup shaped ears with a minority being low set only. In 34 $(68 \%)$ the ear abnormalities were bilateral.

Two thirds of the patients had middle ear problems, consisting of ossicular malformations, stapedius tendon abnormalities or chronic serous otitis media, or both, resulting in conductive hearing loss.

Nineteen (38\%) suffered inner ear abnormalities of the cochlear or semicircular canals resulting in severe sensorineural deafness, and 15 $(30 \%)$ had severe mixed hearing loss; all required hearing aids.

Eight patients had cleft lip or palate, or both, and four of these had evidence of glue ears. Of the 28 children with choanal atresia or stenosis, $22(78 \%)$ had bilateral external ear abnormalities.

\section{OCULAR MANIFESTATIONS}

Coloboma affecting either one or both eyes was detected in 43 patients of the 47 examined by an ophthalmologist. Of these, only 16 had iris coloboma (two of these 16 had partial defects shown on transillumination of the iris). Two patients had normal fundi with iris coloboma, but 28 patients had fundal colobomata with normal irides. There was one case of eyelid colobomata, which has not previously been reported in patients with CHARGE association.

Colobomata affected the posterior segment in 38 of the 50 patients, this was bilateral in 32 patients, and in all except nine eyes (in five patients) the optic disc was involved. Quantitative assessment of vision has been possible in 13 patients; we found acuity of eyes with disc coloboma varied from Snellen 6/9 to bare light perception. One patient had a retinochoroidal coloboma without optic disc involvement and vision was $6 / 5$. Segmental hypoplasia of the optic nerve head was reported in four eyes (in all cases it was the patient's better eye) and their acuity ranged from $6 / 6$ to $6 / 18$.
Microphthalmos (considered to be part of the 'typical coloboma' spectrum in that the defect arises from incomplete apposition of the fetal fissure of the optic cup) was present in 22 of the 50 patients: it was bilateral in nine, right sided in six, and left sided in seven. However, it was predominantly mild with only two patients having eyes that offered no useful vision.

Nystagmus was present in 13 patients with visual acuity ranging from $6 / 9$ to "bare navigation'. Strabismus was detected in 16 patients (seven divergent, six convergent, and three variable). Refractive errors were common (myopia, hypermetropia, and astigmatism), and in eight patients there was more than two dioptres of anisometropia. Spectacles have improved visual performance in 10 patients.

Despite copious lubrication and lateral tarsorrhaphy, three patients with facial palsy had corneal scarring.

Retinal detachment as a complication of colobomata occurred bilaterally in two patients and, at the time of diagnosis, one eye in each case was already inoperable. Both of the fellow eyes have required vitreoretinal surgery with removal of the lens and silicone oil exchange with useful vision presently retained.

\section{GENITAL AND ENDOCRINE ABNORMALITIES}

Of the 29 male patients, 28 (96\%) had external genital abnormalities including at least $25(86 \%)$ with micropenis (two were not documented); 17 $(58 \%)$ had bilateral undescended testis. Of 21 male patients over 1 year of age, 15 had growth retardation and cryptorchidism, two had growth above the 3rd centile and cryptorchidism, four had normal growth and descended testes. Full endocrine assessments have not been completed on all the older children in our study; however, one boy was found to be growth hormone deficient. Four of the boys over 9 years old were studied for gonadotrophin deficiency and all were found to have flat luteinising hormone releasing hormone responses and negligible testosterone rise to human chorionic gonadotrophin.

\section{OTHER ASSOCIATED FEATURES}

Renal abnormalities (malrotation, hydronephrosis, reflux) were present in 12 (24\%) patients. Thirteen $(26 \%)$ patients had laryngeal malformations (laryngomalacia, laryngeal clefts, abnormal aryepiglottic folds). Forty four $(88 \%)$ had feeding problems and, of these, $20(45 \%)$ had gastro-oesophageal reflux. Five patients (11\%) had oesophageal atresia with tracheooesophageal fistula.

Skeletal abnormalities were present in 20 $(40 \%)$ patients. Eleven patients had hemivertebrae or scoliosis; nine had abnormalities of the extremities, predominantly syndactyly or clinodactyly.

\section{GROWTH RETARDATION}

Eleven neonates $(22 \%)$ had intrauterine growth retardation and all subsequently continued to be growth retarded. However, not all children with 
Table 5 Details of patients over 1 year of age $(n=34)$

\begin{tabular}{|c|c|c|}
\hline & $\begin{array}{l}\text { Failure to } \\
\text { thrive: height } \\
\text { and weight } \\
<3 r d \text { centile } \\
(n=26)\end{array}$ & $\begin{array}{l}\text { Relatively normal } \\
\text { growth: height and } \\
\text { weight }>3 \text { rd centile } \\
(n=8)\end{array}$ \\
\hline $\begin{array}{l}\text { Feeding difficulties } \\
\text { Gastro-oesophageal reflux } \\
\text { Nissen's fundoplication } \\
\text { Larynx/pharynx problems } \\
\text { Facial palsy } \\
\text { No of major operations } \\
\text { (minimum/maximum) } \\
\text { Average/patient }\end{array}$ & $\begin{array}{c}24 \\
15 \\
6 \\
8 \\
15^{*} \\
1 / 5 \\
1 \cdot 4\end{array}$ & $\begin{array}{l}4 \\
1 \\
0 \\
0 \\
1^{*} \\
0 / 1 \\
0 \cdot 5\end{array}$ \\
\hline
\end{tabular}

${ }^{*}$ Of the children with facial palsy and failure to thrive, all 15 had feeding difficulties and 10 gastro-oesophageal reflux; the one child with relatively normal growth had both feeding difficulties and gastro-oesophageal reflux.

postnatal growth retardation had poor intrauterine growth. In the first year of life, 39 patients had growth retardation (defined here as weight falling to below the 3rd centile), four patients were not growth retarded, five died at less than 2 months of age, and two were too young for assessment. Of the 34 children over 1 year old, $26(76 \%)$ had growth retardation and eight $(24 \%)$ were on or above the 3 rd centiles. Data relating to the clinical management of these 34 patients is presented in table 5 .

\section{DEVELOPMENTAL DELAY}

Twenty six patients (52\%) with CHARGE association had developmental delay; eight (17\%) did not. Sixteen were too young for assessment. Of those with normal developmental none had BPCA. Of the eight children with normal development, seven had either colobomata or auditory problems but not both.

A variety of neurological signs were noted in these patients. Facial palsy was observed at or soon after birth in 21 patients (right in 12, left in seven, with two bilateral). Most palsies were congenital with only three being acquired. Nine patients had microcephaly (defined here as a head circumference below the 3 rd centile when measured at birth). Of these nine, all had developmental delay but the converse was not found. We found no correlation between the severity of mental retardation and the presence of microcephaly. Eleven patients (22\%) had abnormalities shown on computed tomography: eight had mild atrophy, one had an occipital encephalocele, one had agenesis of the corpus callosum, and one had communicating hydrocephalus. Fourteen patients $(28 \%)$ had abnor-

Table 6 Association between abnormal neurological findings, hypotonia, and facial palsy

\begin{tabular}{llll}
\hline & Hypotonia & Facial palsy & $\begin{array}{l}\text { Hypotonia } \\
\text { and facial } \\
\text { palsy }\end{array}$ \\
\hline $\begin{array}{l}\text { Abnormal computed } \\
\text { tomogram (n=11) }\end{array}$ & 6 & 5 & 4 \\
$\begin{array}{c}\text { Abnormal electro- } \\
\text { encephalogram (n=14) }\end{array}$ & 11 & 8 & 7 \\
$\begin{array}{c}\text { Abnormal computed } \\
\text { tomogram and } \\
\text { electroencephalo- }\end{array}$ & 6 & 5 & 5 \\
$\begin{array}{l}\text { gram (n=7) } \\
\text { Deaths (n=13) }\end{array}$ & $5^{*}$ & 6 & 1 \\
\hline
\end{tabular}

*Of the eight children without hypotonia who died, two were
hypertonic, three had unknown tone, and three normal tone. mal findings on electroencephalography. The association between abnormal neurological findings, hypotonia, and facial palsy is shown in table 6. A number of patients were reported by their parents to have infantile spasms in the absence of any fever. ${ }^{5}$

\section{Discussion}

Management of patients with CHARGE association is a challenging task both for the general paediatrician and other specialist teams. Integrated management is vital if these children are to reach their full potential.

In our attempt to ascertain from hospital records a complete list of patients with CHARGE association, we found a surprisingly high number of children with two or three of the main features who could not be categorised as having CHARGE association under the current nomenclature yet clearly appeared to be of the same broad phenotype. They also exhibited many of the associated anomalies found in CHARGE association such as those involving the vertebra, kidneys, facial palsy, short neck, hypertelorism, and widely spaced nipples.

Diagnosis, although straightforward in patients with all six of the main features of CHARGE, can become more difficult in several ways. First, diagnosis of CHARGE association in a neonatal girl may be more difficult than in a boy because abnormalities of external genitalia do not occur. Therefore only five of the criteria for CHARGE are available, and growth retardation may not yet be apparent. This is where the other associated abnormalities, particularly facial palsy, may be of value in the initial diagnosis. Second, difficulties of diagnosis may also be encountered with a neonatal boy who has coloboma, micropenis, and low set ears but no heart defect or choanal atresia. A final diagnosis of CHARGE association would require specific subsequent confirmation of developmental retardation especially as none of his lesions in themselves would affect childhood development. For most cases, however, the typical facial appearance (fig 2) of lop/cup shape protruding ears and facial asymmetry should be enough to alert the general paediatrician especially if there is cyanosis or respiratory distress in the newborn. Most cases of CHARGE association have been sporadic but in some there is clearly a genetic component ${ }^{2} 6-9$ with both autosomal dominant ${ }^{10}$ and recessive ${ }^{11}$ transmission having been reported. Although karyotypic analysis is generally reported as normal in these patients, it is important to identify any chromosomal abnormalities before making a diagnosis of CHARGE association as a variety of chromosomal abnormalities can occur in association with colobomata and choanal atresia. In view of the overlap between CHARGE association and the DiGeorge sequence, it is important to confirm the integrity of chromosome 22 and to evaluate for thymic and parathyroid dysfunction. ${ }^{12}$

For optimal management, the patient with CHARGE association should ideally be referred to a hospital that can undertake all areas of specialist treatment and management. This 
Figure 2 Typical appearance of CHARGE association, particularly apparent are the low set dysmorphic ears and facial asymmetry.

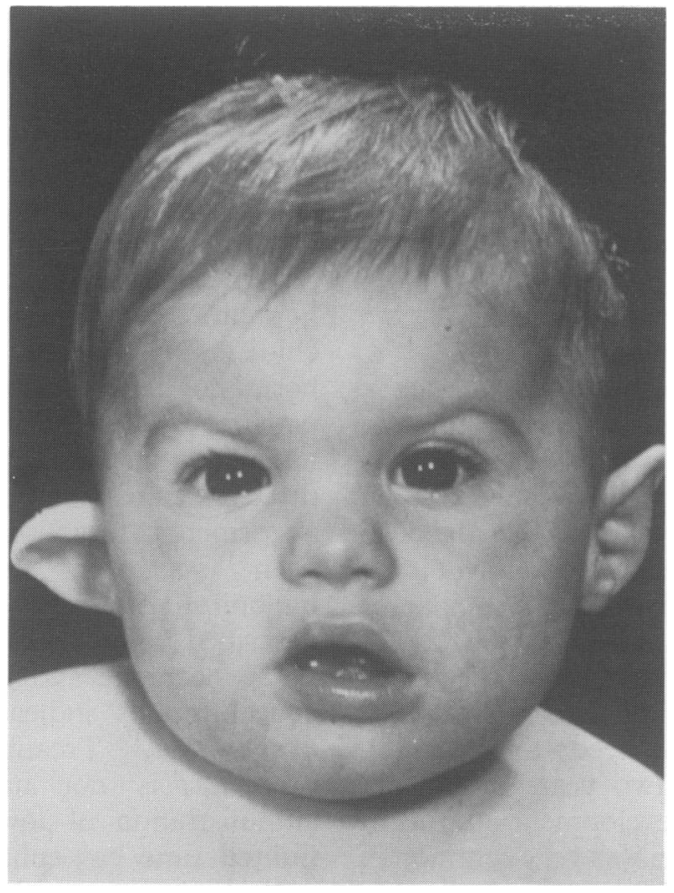

helps in long term follow up, benefits the parents, and most importantly it offers an integrated, multidisciplinary approach. In this way surgical management can unify with investigations that also require a general anaesthetic. This requires active coordination and cooperation between the appropriate specialities. In our series of patients it is probable that a more unified multidisciplinary approach could have reduced the number of general anaesthetics by at least $25 \%$ and this may have helped to reduced morbidity and possibly mortality. High postoperative mortality may reflect the laryngopharyngeal incoordination, which can be present even when there is no structural anomaly. Over half of the deaths in our series of patients were attributable to aspiration of secretions. It is clearly important to be aware of this risk when considering the postoperative management and to realise that most of these patients have complications after anaesthesia. The respiratory problems encountered in CHARGE association are secondary to the oro/nasopharyngeal, oesophageal, and cardiac manifestations. The most severely affected group were unable adequately to swallow their secretions. They required tracheostomies to avoid recurrent aspiration of secretions and, after this procedure, needed very frequent suction for a prolonged period of time.

\section{CARDIOLOGICAL EVALUATION}

We found that heart disease tended to be severe in CHARGE association. Tetralogy of Fallot and atrioventricular septal defects were the most common cyanotic cardiac defects in our group of patients and, as reported previously, patent ductus arteriosus was a common finding either alone or associated with more severe lesions. ${ }^{13}$ We did not find the high incidence of aortic arch anomalies cited by other authors. ${ }^{14}$
As in previous reports, however, conotruncal defects were prominent. ${ }^{15}$

For a blue neonate presenting at a referring hospital, once an oral airway is established and the child remains cyanosed the cause is likely to be cyanotic congenital heart disease. The infant should be stabilised and transported to a regional referral centre.

Neonates who were given prostaglandin E2, usually at the referring hospital for cyanotic heart disease, had a high mortality (table 3 ). This poor outcome may reflect the fact that these patients were critically ill neonates. It was subsequently shown that three of these patients had high pulmonary blood flow, however, and in retrospect they should not have received prostaglandin during transfer. Conversely, some patients with restrictive pulmonary blood flow survived transfer without receiving prostaglandin.

Patients with CHARGE association may require an early shunt procedure before a later definitive repair. It may be possible to send patients directly for cardiac surgery on the basis of echocardiographic findings alone; however, cardiac catheterisation may be necessary to identify anomalous subclavian vessels or to rule out peripheral pulmonary stenosis, or both.

In our experience, parents may decline treatment if their child has multiple defects, even if in our opinion their child is likely to survive their cardiac surgery.

\section{MANAGEMENT OF CHOANAL ATRESIA}

Bilateral posterior choanal atresia is an uncommon congenital abnormality with an incidence of one in 5000-8000 live births and presentation is with cyclical cyanosis relieved by crying. If choanal atresia is unilateral, persistent nasal discharge occurs. Anatomically there is failure to develop patency between the nasal cavity and nasopharynx, which occurs between the 25th to the 45th day of embryonic life.

Once the diagnosis of choanal atresia has been confirmed, stabilisation of the neonate by oral airway should be followed by urgent transfer to a regional centre. Computed tomography has emerged as the diagnostic radiological procedure of choice in evaluating posterior choanal atresia. ${ }^{16}$ It gives the surgeon detailed anatomical information about the type of atresia or stenosis - that is, bony or membranous, unilateral or bilateral-and this clearly may influence the choice of surgical approach in repair of the lesion. In our experience the transnasal repair is far more satisfactory than the transpalatal approach. Nasal stents are usually required for six weeks and patients may require further dilatations to guarantee nasal patency. It is suggested that any child with abnormalities of the choanae has investigations for associated structural problems in other systems. ${ }^{17}$ As we found a close association between BPCA and chronic serous otitis media one could argue a strong case for prophylactic grommets.

It should be possible to scan the temporal bones and brain at the same time and so prevent a repetition of general anaesthesia for each of these procedures. There should be prompt 
investigation for possible cardiac anomalies or tracheo-oesophageal atresia as either of these major defects, especially when associated with choanal atresia, carry a high risk of mortality (fig 1 and table 3). This attrition may be, in part, due to the fact that these children need a number of general anaesthetics very early in life.

\section{EAR ABNORMALITIES}

The initial assessment consists of examination of the tympanic membranes to exclude a middle ear effusion. Then brain stem evoked audiometry may be used to help assess the level of hearing, and computed tomography of the temporal bone is used to exclude ossicular or inner ear abnormalities.

The insertion of grommets for chronic serous otitis media may make an enormous difference to the quality of life, and needs to be undertaken early as the first two years of life are vitally important in the development of speech. Chronic serous otitis media was very common in patients with CHARGE association, and many required early myringotomies with insertion of grommets, which resulted in rapid improvement in language development and balance. Often three or four repeat procedures were necessary when they were older at a time when one would expect middle ear effusions to have disappeared. It is also important to recognise that, even in the presence of structural anomalies or sensorineural deafness, alleviating glue ear can be beneficial. Assessment by an audiological physician and the prescribing of hearing aids for the more severely deaf is essential. Involvement of the peripatetic teacher of the deaf at an early age will allow counselling for parents and offer better provision for educational needs.

\section{OPHTHALMOLOGICAL REVIEW}

An initial examination by an ophthalmologist may show an important ocular defect, alternatively it may detect a subtle coloboma with little relevance to ocular morbidity, but will aid the diagnosis of the CHARGE association. Anisometropia (a difference in refraction of more than two dioptres between eyes) and strabismus are both causes of amblyopia, which are potentially amenable to occlusion treatment. Regular six monthly review is advised for the children with structural abnormalities as complications can ensue, such as retinal detachment or corneal exposure. Early intervention with copious ointment lubrication and, where this is insufficient, lateral tarsorrhaphy, may prevent corneal scarring and even perforation. Assessment of visual function is important to maximise potential for education as spectacles or low visual aids may improve visual performance.

\section{GENITOURINARY AND ENDOCRINE} ABNORMALITIES

The presence of micropenis and undescended testicles makes the early diagnosis of CHARGE association easier in boys. There has been a report of labial hypoplasia in two females over 15 years old but similar findings were not established in our series of 21 girls.

There appeared to be a direct association between growth retardation in the boys and bilateral undescended testis. This may be a consequence of more pronounced hypothalamic hypopituitarism in the group with cryptorchidism. Of those tested, however, growth hormone deficiency was only found in one patient. Follicle stimulating hormone and luteinising hormone deficiencies were found in three of our patients, but most have not had full assessments. Hypothalamic dysfunction has been suggested as a cause of the hypopituitarism, ${ }^{3} 18$ whereas other reports have described high concentrations of follicle stimulating hormone and low baseline testosterone concentrations indicating a primary gonadal dysfunction. ${ }^{19}$ Treatment for these particular problems is not universally accepted but administration of low dose androgens for a limited time has enhanced penile growth. ${ }^{20}$

It is important to look specifically for structural kidney abnormalities that can be associated with reflux. We found that facial palsy was often present in patients with renal problems and the lesions tended to be on the same side of the body.

\section{GROWTH RETARDATION}

Feeding difficulties were a major feature in patients who failed to thrive. The diagnosis of gastro-oesophageal reflux was made by barium swallow but the inert nature of barium sulphate may underestimate the number of patients with reflux. Therefore $\mathrm{pH}$ study techniques would be more appropriate in patients with feeding difficulties. Pharyngeal incoordination was present in 14 of our patients and, in those who underwent microlaryngobroncoscopy, structural defects were often found (that is, clefts of the larynx or pharynx, short aryepiglottic folds, and laryngomalacia). Many mothers expressed difficulty in weaning the children to any form of lumpy solid food. Our findings indicate that facial palsy was associated with feeding problems or gastroesophageal reflux, or both, and could therefore be used as a useful predictor for these and also for failure to thrive.

\section{DEVELOPMENTAL DELAY}

Evaluation of visual and auditory systems is vital but, in our experience, is easily overlooked by surgical teams intent only on achieving survival from a major cardiac, choanal, or tracheo-oesophageal repair. However, if all handicaps can be defined early then steps can be made to locate the appropriate resources for education as well as giving the parents as much information as possible. The diagnosis of mental retardation should be made with caution in anyone with impaired hearing and vision as they are inherently understimulated. Deafness, if not recognised early, may present with delay in language; poor vision may cause delay in fine motor skills. Children with both defective hear- 
ing and vision may present at an earlier date with delay in gross motor skills and problems with balance. In some cases they may even appear autistic. Mental retardation may be present but should only be diagnosed when the extent of the sensory deficit is known and when the child has been in an adequate educational programme. We found, as with others, ${ }^{21}$ that major strides in development were often made by patients with CHARGE association once parents realised that mental retardation was not inevitable and the potential of their children was explained fully. We therefore consider that mental retardation should not be used as one of the features of the CHARGE association. Instead, the term 'developmental delay' may be more appropriate.

Two patients attended special schools because of their small physique but relatively mild sensory impairment. It is interesting that when these children were first assessed developmentally (between 2 and 3 years old) they had extremely poor scores, particularly in language and fine motor coordination. Normal schooling seemed out of the question and the parents were advised of this. Subsequent assessments proved this to be wrong. Slow initial development may be a consequence of prolonged hospitalisation for major surgery in the first year of life combined with lack of active management for their sensory deficit.

\section{WHO'S IN CHARGE?}

Patients with CHARGE association require multidisciplinary management. This may be difficult to coordinate; surgical units receiving sick neonates would do well to have a check list of main and associated abnormalities to be investigated in dysmorphic children. Although initial presentation of new patients is likely to be for the management of congenital heart disease, choanal atresia and/or tracheo-oesophageal fistula, however, it seems inappropriate for cardiac or paediatric surgeons to coordinate long term management of these patients. In our experience patients with choanal atresia generally required more surgical procedures and investigations under anaesthetic. We would therefore suggest the specialist paediatric ear, nose, and throat surgeon (as these patients are also likely to have chronic ear problems including hearing aid provision), the general paediatrician, and the district community paediatrician to be the most appropriate coordinators ofmultidisciplinary long term management of these patients.

1 Hall BD. Choanal atresia and associated multiple anomalies. 7 Pediatr 1979;95:395-8.

2 Pagon RA, Graham JM, Zonana J, Young SL. Congenital heart disease and choanal atresia with multiple anomalies: CHARGE association. $\mathcal{F}$ Pediatr 1981;99:223-7.

3 Davenport SLH, Hefner MA, Mitchell JA. The spectrum of clinical features in CHARGE syndrome. Clin Genet 1986;29:298-310.

4 Oley CA, Baraitser M, Grant DB. A reappraisal of CHARGE association. $\mathcal{f}$ Med Genet 1988;25:147-56.

5 Curatolo $P$, Libutti G, Brinchi V. Infantile spasms and the Curatolo P, Libutti G, Brinchi V. Infantile spasms and the
CHARGE association. Dev Med Child Neurol 1983;25: 367-73.

6 Collum LMT. Uveal colobomata and other anomalies in three generations of one family. $\mathrm{Br} \mathcal{F}$ Ophthalmol 1971;55: 458-61.

7 Ho CK, Kaufman RL, Podos SM. Ocular colobomata, cardiac defect, and other anomalies: a study of seven cases including two sibs. $\mathcal{f}$ Med Genet 1975;12:289-93.

8 Hittner HM, Hirsch NJ, Kreh GM, Rudolph AJ. Colobomatous microphthalmia, heart disease, hearing loss and mental retardation: a syndrome. 7 Pediatr Ophthalmol Strabismus 1979;16:122-8.

9 Warburg $M$. Ocular coloboma and multiple congenital anomalies: the CHARGE association. Ophthal Paediatr Genet 1983;2:189-99.

10 Mitchell JA, Giangiacomo J, Hefner MA, Thelin JW, Pickens JM. Dominant CHÁRGE association. Ophthalmic Paediatr Genet 1985;6:31-6.

11 Metlay LA, Smythe PS, Miller ME. Familial CHARGE syndrome: clinical report with autopsy findings. AM $\mathcal{J} M e d$ Genet 1987;26:577-81.

12 De la Chapelle A, Herva R, Koivisto M, Aula P. A deletion in chromosome 22 can cause DiGeorge syndrome. Hum Gene 57:253-6.

13 Cyran SE, Martinez R, Daniels S, Dignan P St J, Kaplan S. Spectrum of congenital heart disease in CHARGE association. $\mathcal{F}$ Pediatr 1987;110:576-8.

14 Lin AE, Chin AJ, Devine W, Park SC, Zackai E. The pattern of cardiovascular malformation in CHARGE association. Am $\mathcal{F}$ Dis Child 1987;141:1010

15 Siebert JR, Graham JM Jr, MacDonald C. Pathologic features of the CHARGE association: support for involvement of the neural crest. Teratology 1985;31:331-6.

16 Brown OE, Burns DK, Smith TH, Rutledge JC. Bilateral posterior choanal atresia: a morphological and histologic posterior choanal atresia: a morphological and histologic Otorhinolaryngol 1987;13:125-42.

17 Duncan NO, Miller RH, Catlin FI. Choanal atresia and associated anomalies: the CHARGE association. Int $\mathcal{f}$ Pediat ciated anomalies: the CHARGE
Otorhinolaryngol 1988;15:129-35.

18 August PA, Rosebaum KN, Friendly D, et al. Hypopituitarism and the CHARGE association. $\mathcal{F}$ Pediatr 1983;103: 424-5.

19 Pardo JM, Chua C. The CHARGE association in a male newborn infant. Clin Pediatr (Phila) 1989;24:531-3.

20 Burstein S, Grumbach MM, Kaplan SL. Early determination of androgen responsiveness is important in the managemen of microphallus. Lancet 1979;ii:983-6.

21 Goldson E, Smith AC, Stewart JM. The CHARGE association. How well can they do? Am 7 Dis Child 1986;140: 918-21. 